\title{
No pain, no gain? Sentidos e significados atribuídos às dores e aos riscos entre malhar e treinar em academias de ginástica
}

https://doi.org/10.11606/issn.1981-4690.v35i1p1-13

\section{Resumo}

0 objetivo dessa pesquisa etnográfica foi analisar e discutir os sentidos e os significados atribuídos às dores corporais e aos riscos no que diz respeito aos esforços físicos pelos alunos e pelos profissionais de Educação Física em duas academias de ginástica no Rio de Janeiro: uma de pequeno porte em um bairro popular $(P)$ e outra de grande porte em um bairro nobre $(G)$ da cidade. Na linha teórico-metodológica do interacionismo simbólico, foi realizada uma etnografia comparativa no espaço da musculação das duas academias. Observou-se que os "limites" das dores corporais durante os exercícios físicos e as noções de risco à saúde foram representados de formas plurais a depender dos contextos e dos grupos sociais. Os profissionais de ambos os estabelecimentos tendiam a exigir o máximo de esforços físicos dos seus alunos. $\mathrm{Na}$ academia $\mathrm{P}, \mathrm{o}$ culto às dores e aos riscos era uma forma de cuidar de si. Os alunos concebiam o corpo como um "bem" a ser constantemente malhado. Na academia G, privilegiava-se a sociabilidade em função da exaustão dos exercícios físicos. Para os alunos, sentir dor ou estar em risco simbolizava danos ao corpo compreendido como um "patrimônio" a ser treinado. Mais do que um dado físico-biológico representado pelo sacrifício e sofrimento corporal, a forma de sentir dor e o que se entende por risco à saúde podem revelar os múltiplos lugares sociais dos pesquisados. Estes aspectos tornam-se importantes para a produção de conhecimento e a intervenção profissional no campo da Saúde e na área de Educação Física, pois ajudam entender e particularizar as ações e reflexões acadêmico-profissionais na relação com o outro para além do referencial técnico-científico da racionalidade biomédica.

PalavRAS-CHAvE: Educação Física e Treinamento; Antropologia; Risco sanitário; Atividade física; Musculação; Etnografia.

\section{Introdução}

A compreensão de diversos usos do corpo e das práticas corporais a partir de referenciais teórico-metodológicos das Ciências Sociais vem sendo explorada cada vez mais pelo campo da Saúde ${ }^{1,2}$ e pela área de Educação Física ${ }^{3,4}$. No que diz respeito especificamente à construção sociocultural da dor, o âmbito esportivo se torna, por vezes, o principal objeto dessa análise 5 .

Observa-se que a dor é cultuada pelo atleta a fim de demonstrar que alcançou o seu "limite" de desempenho, mas, ao mesmo tempo, há a tentativa de evitá-la para não prejudicar o rendimento do corpo ${ }^{6}$. Assim, para muitos, concretiza-se a ideia de que é preciso respeitar a dor atlética evitando anestesiá-la ${ }^{7}$. Dessa forma, sendo as dores corporais rotineiras no âmbito esportivo, é importante compreender como o seu escopo simbólico se projeta em outros âmbitos da sociedade contemporânea ${ }^{8,9}$.

O desempenho atlético do esporte no que diz respeito à gestão das dores corporais pode ser visto ressignificado nos espaços da musculação em academias uma vez que os pressupostos do treinamento esportivo, por vezes, focam na
*Escola de Educação Física e Desportos, Universidade Federal do Rio de Janeiro, Rio de Janeiro, RJ, Brasil. **Instituto de Estudos em Saúde Coletiva, Universidade Federal do Rio de Janeiro, Rio de Janeiro, RJ, Brasil. 
exaustividade dos alunos ${ }^{10,11}$. Geralmente, o profissional de Educação Física responsável por supervisionar e prescrever os treinamentos nas academias é considerado um ator importante para mediar esses desconfortos físicos, tanto na sua iniciaçáo da dor como rotina para essa atividade quanto no seu próprio manejo ${ }^{12}$.

Revela-se, portanto, a importância deste estudo haja vista que, a depender do contexto socioeconômico e cultural das academias, a presença de dor pode tornar plural a relação dos sujeitos no engajamento nas práticas corporais, sugerindo questionar os múltiplos lugares sociais do profissional de Educação Física nesses espaços. Ademais, a dor como um dado universal pode ser concebida de modo particular de acordo com determinados contextos e grupos sociais. Assim, investigar este fenômeno tornar-se importante para a intervenção na Saúde ${ }^{13,14}$, pois ainda há uma visão etnocêntrica arraigada em muitos pesquisadores e estudos qualitativos neste campo ${ }^{15}$.

Vale lembrar que o presente trabalho entende que a mera ausência de dor não significa sinônimo de saúde. Além disso, este texto

\section{Metódo}

Afiliado a linha teórico-metodológica do interacionismo simbólico, este trabalho compreende que as relaçóes sociais cotidianas do face a face em um contexto microscópico podem revelar elementos simbólicos que perpassam determinado segmento da sociedade ${ }^{18,19}$. O empreendimento etnográfico representado pela observação participante oferece uma análise que oscila entre os acontecimentos singulares e a sua representação em uma realidade mais ampla.

Para apreender a diversidade de elementos relacionados aos sentidos e aos significados atribuídos às dores, buscou-se uma análise etnográfica comparativa abrangendo duas academias inseridas em realidades socioeconômicas e culturais distintas da cidade do Rio de Janeiro. Diante de certa polarização entre grandes e pequenas academias ${ }^{20,21}$, bem como pelas diferenças de usos do corpo nesses locais em função da característica financeira da regiáo e do público ${ }^{22-25}$, foi selecionada uma academia de pequeno porte $(\mathrm{P})$ relativiza a ideia de que os indivíduos buscam rechaçar a dor como ideal de boa saúde e que possui uma relação proporcional à gravidade de uma suposta lesão ${ }^{16}$. Isso se pauta na perspectiva de que a construçáo dos sentidos e dos significados atribuídos ao corpo estabelecese relacionalmente no encontro com o outro, podendo revelar, assim, as concepções acerca dos esforços físicos indicativas das construçóes identitárias e das interações simbólicas cotidianas constituintes das atuaçóes dos profissionais e dos alunos nas academias. De acordo com LE BRETON ${ }^{6}$, "A disposição de assumir riscos ou de recusá-los, ou mesmo de ignorá-los totalmente, nâo corresponde ao mesmo atributo em uma classe e em uma cultura e em outra." (p. 17).

Assim, o objetivo desta pesquisa etnográfica foi analisar e discutir os sentidos e os significados atribuídos às dores corporais e aos riscos no que diz respeito aos esforços físicos pelos alunos e pelos profissionais de Educaçáo Física em duas academias de ginástica no Rio de Janeiro. O presente manuscrito faz parte de uma tese de doutorado desenvolvida no Instituto de Estudos em Saúde Coletiva da Universidade Federal do Rio de Janeiro ${ }^{17}$.

de um bairro conhecido como popular (Cidade de Deus) e uma academia de grande porte (G) de um bairro considerado como nobre (Barra da Tijuca).

O foco da observação se direcionou a interação entre os profissionais de Educação Física e os alunos que faziam parte daqueles cenários empíricos. Assim, os sentidos e os significados atribuídos às dores corporais por esses atores sociais foram analisados em funçáo predominantemente a partir dos contatos face a face e na presença do etnógrafo, isto é, “[...] Diz respeito à estrutura dos encontros sociais - a estrutura daquelas entidades da vida social que surgem sempre que as pessoas entram em presença física imediata umas das outras." ${ }^{19}$ (p. 233).

Os profissionais estavam na faixa etária entre vinte a trinta anos de idade e os alunos, entre quinze a cinquenta anos. $\mathrm{Na}$ academia $\mathrm{P}$, as pessoas eram orientadas por um único profissional de Educação Física por turno. Nessa academia, havia um total aproximado de mil alunos 
matriculados no estabelecimento, mas apenas duzentos frequentavam o local e, em média, entre dez a trinta pessoas circulavam por hora pela sala de musculação. Já na academia G, os alunos eram supervisionados por três a sete profissionais de Educaçáo Física e também por um a três estagiários da área por turno. Ali havia cerca de três mil pessoas cadastradas no estabelecimento e oitocentos alunos praticantes da musculação, tendo por volta de sessenta a cento e vinte frequentadores por hora no local. A proposta foi delimitar diferentes profissionais de ambas as academias a fim de explorar a multiplicidade de espectros de interaçóes sociais com seus diversos alunos. Sendo assim, vale ressaltar que o presente estudo não objetivou aprofundar os marcadores e as trajetórias sociais dos pesquisados uma vez que a perspectiva teórico-metodológica aqui não privilegia "[...] ver tipos de pessoas como

\section{Resultados e Discussão}

O antigo chavão "no pain, no gain" que permeou a ideologia esportiva e do culto ao corpo durante a década de oitenta ${ }^{27}$ é ainda muito presente nas representaçôes sociais das práticas corporais nas academias de ginástica. Entretanto, esse chavão não atravessou da mesma maneira os espaços $\mathrm{da}$ musculação das academias e entre os diferentes grupos sociais analisados. Em outras palavras, estar no "limite" ou não da dor corporal se diversificou a depender dos contextos e dos contatos face a face. Nas palavras de $S_{A R T I}{ }^{28}$ :

A dor como realidade social é simbolizada, ainda, mediante os distintos lugares sociais dos indivíduos. Dentro de uma mesma sociedade, os indivíduos são portadores de condiçốes sociais diferenciadas, de acordo com as clivagens sociais, entre elas, as de gênero, de classe e etnia, qualificando a realidade da dor. Pode haver maior ou menor tolerância à dor, conforme aquilo que do indivíduo se espera, segundo seu lugar social. (p. 9)

Nesse contexto, foi possível observar que as dores estavam ligadas a diferentes atributos corporais almejados e a distintas ideias de risco à saúde entre alunos e profissionais das academias P e G. As dores nesse trabalho referem-se àquelas relacionadas aos esforços físicos gerados ao longo da realização de categorias analíticas [...] em vez disso, tipos de atividades em que as pessoas se envolvem ocasionalmente." ${ }^{26}$ (p. 68).

Foram utilizados dois diários de campo entre Julho/2012 a Julho/2013: o empreendimento etnográfico comparativo teve duração de doze meses na academia P e dez meses na academia G. Por duas vezes na semana, durante quatro horas no período entre a tarde/noite, a observaçáo participante se restringiu primordialmente ao espaço da musculação. A aproximação e a inserção nos campos de pesquisa assim como o processo de reflexividade do pesquisador e a convivência ou relação deste com seus interlocutores podem ser vistos pormenorizadamente em SiLva ${ }^{17}$.

Esta pesquisa foi aprovada e autorizada pelo Comitê de Ética em Pesquisa do Instituto de Estudos em Saúde Coletiva da Universidade Federal do Rio de Janeiro.

práticas corporais e que, por vezes, deveriam ou não ser evitadas no espaço da musculação. Assim, a partir do material empírico, foram criadas duas categorias com diferentes lógicas simbólicas acerca das dores e riscos: malhar e treinar. Após esclarecer essas formas de se engajar nas práticas corporais, seráo apresentadas como tais categorias permearam as academias $\mathrm{P}$ e $\mathrm{G}$.

\section{Entre malhar e treinar}

A depender dos contatos face a face em determinados contextos produzidos na musculação, as concepções referentes às dores se modificavam em ambos os estabelecimentos. Isto é, as noçóes de se fazer esforço físico na musculação no "limite" ou não das dores eram plurais e dinâmicas. As dores eram um dos elementos mais relevantes nessa construção de como ser um frequentador de academia.

As discussóes sobre dor nos rituais de sacrifícios delineada por Mauss e HuberT ${ }^{29}$ ou nos ritos de passagem de Turner ${ }^{30}$ e de Gennep ${ }^{31}$ podem ser vistas pelas interaçôes e performances que tendem a elevar o status da pessoa e a coesão coletiva ${ }^{19,32}$. Isto é, não eram raras as situaçôes em que os profissionais de Educação Física e os alunos mais experientes, avançados ou veteranos ditavam os 
sacrifícios aos os alunos iniciantes ou novatos que sofriam as abnegaçóes quanto a esses tipos de dores com os corpos no "limite".

Os profissionais e os alunos ressignificavam os desconfortos físicos durante a realização cotidiana de exercícios físicos na musculação. Os diferentes sentidos atribuídos por esses atores sociais transitavam entre duas categorias: treinar ou malhar. A categoria nativa de malhar era atrelada à ideia de se exercitar vigorosamente no sentido de "espancar", "surrar", "dar pancadas" e "machucar" o corpo. Treinar se alinhava à noção de "adestramento" no sentido de tornar o corpo "apto", "capaz" e "habilitado" a partir de diretrizes técnico-científicas do treinamento desportivo, evitando qualquer incidente negativo para o organismo durante a realização de exercícios físicos.

$\mathrm{Na}$ academia $\mathrm{P}$, quando eu perguntava para um aluno se o "treino" dele estava rendendo, ele me indagava sobre o que era esse "negócio de treino". Evidentemente eles sabiam o que significava treinar, mas eles compreendiam que realizar as práticas corporais não era um treino. Os profissionais dessa academia também não usavam a expressão "treinar" e privilegiavam a tal "malhação". Em síntese, ali na musculação ninguém treinava, mas malhava no mesmo sentido dado por Coelho Filho ${ }^{33}$ :

A palavra malhar, etimologicamente, tem em si a idéia de mancha (mácula), de tecer e trançar, de bater, contundir e dar pancada, de castigar o corpo, de zombar e escarnecer" (p. 3).

$\mathrm{Na}$ academia $\mathrm{G}$, ao contrário, observava que os profissionais "prescreviam treinamentos" e os alunos "realizavam treinos" na musculação. Quando perguntei a um profissional se os alunos dele "malhavam à risca", isto é, se seguiam integralmente suas prescriçóes, ele me respondeu que: "Infelizmente, não! Muitos malham, mas poucos treinam de verdade de forma séria. A galera que malha não segue as orientaçóes! Fazem por fazer e acabam se lesionando depois. Já quem treina observa tudo: tempo de intervalo, aumento da sobrecarga, a execução do movimento, objetivo preciso, etc.". Este fato era notável na conversa dos alunos se referindo sempre às "metas de treino". Presenciei uma situaçáo em que um profissional da academia $G$ perguntou se a aluna iria malhar e obteve a seguinte resposta: "Por acaso você está falando comigo? Não, vou treinar e não malhar!".

Portanto, na academia $\mathrm{P}$, malhar era legítimo na medida em que sentir dores de esforços físicos era socialmente aceitável para grande parte do público. $\mathrm{Na}$ academia $\mathrm{G}$, poderia ser considerado falta de "competência corporal", pois nesse local eles "treinavam de verdade". Assim, entre malhar e treinar, existiam modos de administrar certos riscos de forma relativizada em dados grupos sociais. Dessa forma, o risco indo até o "limite" caracterizava-se por um modo essencial de vivenciar inúmeras atividades ${ }^{6}$.

Nesse sentido, o engajamento nas práticas corporais era relativamente distinto entre os estabelecimentos. Analisar as racionalidades ligadas às dores do malhar e do treinar pode transparecer que os profissionais e os alunos da academia $G$ seriam mais preocupados com o corpo e com o risco à saúde do que os da academia P. Contudo, os grupos sociais de ambas as academias, profissionais e alunos, tinham as mesmas preocupaçôes com o corpo e com os riscos, porém de modo diferente ao lidarem com as dores derivadas dos esforços físicos. Em outras palavras, a sensação de dor em academias pode ser construída ao longo das próprias experiências com as práticas corporais ${ }^{34}$.

Assim, em ambas as academias, estar ou não sentindo dores fazia parte de um processo liminar contínuo e fluido dos limites em relaçáo às práticas com ou sem esforços físicos. Dessa maneira, nas academias P e G, o exercitar-se com ou sem dores se direcionava para um lado em que cada vez mais precisava esforçar-se no "limite" para sentir esses desconfortos físicos ou, por outro, no sentido de que "sempre" era possível evitar qualquer sensação desse tipo. Portanto, malhar e treinar vinculavamse às circunstâncias e interaçóes responsáveis por produzirem representaçóes plurais acerca do risco por parte dos grupos sociais frequentadores das academias P e G, a saber.

\section{Na academia $P$ do bairro popular da Cidade de Deus}

$\mathrm{Na}$ academia $\mathrm{P}$, grande parte dos alunos atribuía positividade ao fato de estar sentindo dores, pois assim os gastos seriam compensados no estabelecimento. Nesse sentido, para o investimento monetário com a academia valer a pena era necessário também investir no sacrifício e esforço corporal que se traduzia no momento em que a dor física se manifestava:

Luciano: Eu malho pesado porque eu pago, porque se fosse para pegar leve, eu malhava em casa. Sem 
sacrifício, não tem resultado!

Moisés: Você está aqui desde que horas?

Pedro: Meio-dia!

Moisés: Caralho, meio-dia? Já está chegando às seis da noite e você ainda aqui? Você é maluco!

Pedro: Tô na merda! Estou compensando os três dias que a academia ficou fechada por causa do carnaval, vim sofrer um pouquinho pra compensar a perda, paguei e não vim. A academia não deveria ter emendado.

Eu: Caraca, muito tempo!

Funcionário Marcinho: Isso é normal aqui, teve um aluno aí um dia que ficou das treze até às vinte horas.

Quanto mais era difícil manter os pagamentos das mensalidades, mais árduos deveriam ser os esforços físicos ali empreendidos, levando o corpo ao "limite" das dores corporais. Era notória a preocupação dos alunos em se manterem engajados nas práticas corporais de forma intensa e duradoura, pois muitos, ao longo do mês, se organizavam financeiramente para poder pagar a mensalidade da academia.

Alguns pagavam a mensalidade em dia e sempre em espécie durante alguns meses, se exercitando exaustivamente para compensar outros meses em que paravam com as práticas corporais a fim de não comprometer o orçamento familiar. Essa era a estratégia adotada para "manter o corpo em forma”. Esta situação gerava certa rotatividade dos alunos mês a mês indicando o que, no ponto de vista de Palma, Ferreira e Bagrichevsky et al. ${ }^{35}$, certos indicadores "[...] expóem a vulnerabilidade de determinados grupos sociais relacionando-a com a dificuldade de acesso à prática de exercícios físicos, possivelmente, porque há em curso dificuldades reais de natureza socioeconômica e/ou cultural." (p. 132).

Vários exemplos podem ser observados nesse sentido. Um dos alunos conseguia pagar a mensalidade somente por dois meses consecutivos. Ele dizia que "inchava" com a prática de exercícios físicos e depois aproveitava o que tinha "ganho" em um mês "parado". Já quando estava "perdendo corpo", retornava ao estabelecimento e assim se mantinha ao longo do ano nesse "vai e vem" de corpo-academia. Outro aluno se exercitava durante um mês ao extremo para emagrecer, sem beber álcool e realizando exercícios físicos de todos os tipos.
Posteriormente, compensava bebendo e gastando dinheiro em tudo que desejava. Como tinha se "guardado" em janeiro e "gastado" em fevereiro, depois, em abril, voltaria a se "guardar" para no mês de maio "abusar". A recepcionista comentava que quando um aluno pagava dois meses seguidos de uma só vez era porque tinha ganho muito dinheiro em determinada época ou estaria bem focado em relaçáo ao que queria com o corpo.

Para SASSATELLI ${ }^{22}$, a academia pode ser considerada um espaço protegido onde se permite "fazer uma pausa", "soltar", "afastar-se de compromissos normais", etc. No caso da academia P, observava que esse estabelecimento configurava-se como uma "necessidade" para seus frequentadores. O culto compulsório ao corpo, às dores e aos riscos para esses alunos caracterizava-se como um modo de compartilhar determinadas práticas entre seus grupos sociais, uma forma de se inserir no mundo por meio de determinado volume corporal. Isso dialoga com a perspectiva de Helman ${ }^{13}$ quando afirma que "Cada cultura possui sua linguagem de sofrimento própria, que faz a ligação entre as experiências subjetivas de mal-estar e o seu reconhecimento social. Os fatores culturais determinam quais os sinais ou sintomas são percebidos como anormais [...]" (p. 107).

Nem os alunos e nem a própria academia $\mathrm{P}$ tinham o interesse de planos de pagamentos bimestrais, trimestrais, semestrais ou anuais, pois a vida financeira de todos ali era descontínua e insegura. Eu observava, e os próprios profissionais comentavam, que a academia P costumava ficar mais cheia na primeira quinzena do mês pelo "dia do pagamento" e depois esvaziava pelas contas que deveriam ser pagas. Assim, os responsáveis do estabelecimento sabiam se determinado mês ia lucrar "mais ou menos" a depender de como fosse a adesão de novos e antigos alunos nas primeiras semanas.

Existia também um "frenesi" do aluno em querer aproveitar tudo que o estabelecimento pudesse oferecer em termos de práticas corporais. Assim, os alunos usavam o espaço da academia ao máximo: realizavam o maior número de exercícios físicos e, se possível, com altas intensidades para compensar o dinheiro que ali investiram. Frequentemente, eu me deparava com os alunos falando que quanto mais exercícios ou mais pesado era a realização dos mesmos, melhor seria a malhação. Segundo eles, tinham que "fazer a moeda valer". Os alunos preferiam o exercício físico " $\mathrm{x}$ " a " $\mathrm{y}$ ", porque "dava para sentir mais o corpo" ou que "dava para pegar mais peso e 
fazer o movimento em uma amplitude maior", o que inevitavelmente causaria mais dores. Observava alunos que malhavam até o limite do número de repetiçóes que podiam aguentar de determinado exercício físico e, logo em seguida, realizavam pausas de alguns segundos para recomeçarem o mesmo movimento no sentido de atingirem índices de dores cada vez maiores. Em várias situaçóes, os alunos disputavam também o local e o grau das dores de esforços físicos.

Todos estes achados diferem do trabalho de $\mathrm{S}_{\mathrm{ABINO}}{ }^{36}$ em que a dor tinha o sentimento de pertencer ao grupo voltado à adoração muscular. Em algumas ocasióes na academia P, o físico parecia ficar secundarizado em relação ao investimento econômico ali realizado. Em parte, o que unia os alunos desta academia era o fato de estarem "malhando" juntos no "limite" vislumbrando os gastos contínuos que possuíam ali.

Cabe ressaltar que essa estratégia de se exercitar ao máximo e sem pausas com o intuito de compensar o financiamento realizado com a mensalidade $\mathrm{da}$ academia P era apenas um exemplo da vida social dos sujeitos de se "doarem corporalmente" naquilo que pagavam com muita dificuldade. Para além dos exercícios físicos da musculação, os alunos contavam que pagavam um rodízio de pizza e ficavam "até dar vontade de vomitar". Bebiam em festas "até caírem" alcoolizados. Usavam drogas "até ficarem muito doidos". Ou seja, usos do corpo que simbolizavam "tudo para fazer valer o dinheiro".

Em contrapartida, havia também uma linha tênue entre usar o corpo no "limite" de forma abundante e saber usá-lo moderadamente. Por vezes, alguns eram criticados por tais feitos de se "doarem corporalmente" dessa maneira "demasiada" ou "inconsequente". Assim, o corpo em exercício físico na academia $\mathrm{P}$ era o corpo do dia a dia "duro" das condiçóes difíceis de vida. Ao mesmo tempo em que deveria torná-lo altamente "utilizável", alguns "limites" poderiam ser "repensados", dialogando com a ideia de que as condiçôes socioeconômicas e culturais dos praticantes ali eram reproduzidas durante as práticas corporais.

Em outras palavras, com base em SHILling ${ }^{37}$, o capital econômico e o capital corporal na academia P pareciam se entrelaçar influenciando consideravelmente as relaçóes dos alunos com suas dores e riscos na prática da musculação. Desse modo, pensando nas interaçóes sociais ali estabelecidas, "Um corpo é uma unidade de equipamento consequencial, e seu dono o está sempre colocando na linha de frente. É claro que ele pode utilizar outros bens capitais em muitos de seus momentos, mas seu corpo é o único que ele nunca pode deixar para trás"38 (p. 159).
Nesse contexto da academia P, os profissionais de Educação Física defendiam e estimulavam o aparecimento de dores nos esforços físicos:

\author{
Prof. José: Isso tá leve, hein? \\ Norma: Que isso? Tá louco? \\ Prof. José: Tá leve sim! \\ Norma: Nem insiste! \\ Prof. José: As pessoas têm que trabalhar em cima do cansaço, \\ tem que ser poucos minutos de descanso também, senão o \\ músculo relaxa demais, tem que trabalhar com ele contraído.
}

Prof. Cobra: Tem alguém chorando aí? Tá sofrendo? Tá morrendo?

Eu: Elas estão no limite! Caraca!

Prof. Cobra: Elas não querem ficar gostosas, então têm que sofrer!

Para esses professores, estimular os alunos a intensos esforços físicos no "limite" das dores era como eles deveriam "cuidar" de quem os procuravam. Os profissionais relatavam que os alunos tinham certos direitos ao pagarem a mensalidade como, por exemplo, receber em troca os benefícios corporais. Dessa maneira, os profissionais entendiam que a presença de dores era um modo de cuidar daqueles que gostariam de evitar certos "fatores de risco à saúde". Certa vez, uma das profissionais avisou as suas alunas que o exercício físico que ela ia propor "era forte, era pra compensar o valor da academia, era pra valer o dinheiro!”.

Grande parte das açóes dos profissionais tinha que estar segura que suas orientaçóes e prescrições de exercícios físicos levavam os alunos ao "limite" corporal. Nesse sentido, exigir menos dos mesmos demonstraria uma espécie de "fracasso profissional". Por isso, o feedback através das reaçóes do aluno que não estaria aguentando a rotina de exercícios físicos era um dado importante para o profissional estar ciente de como a sua atuação estava sendo reconhecida. Os profissionais ficavam contemplados quando um aluno verbalizava que "não aguentava mais" essas prescriçóes, o que os fazia reagir com sorrisos, gargalhadas e piscadelas.

Se o aluno não conseguisse realizar um exercício físico com determinada carga, o profissional em vez de abaixá-la, preferia mudar a forma de execução ou número de repetiçóes que havia estabelecido previamente. Reduzir o peso poderia demonstrar certa fragilidade tanto do aluno quanto do profissional que estivesse ali orientando, por isso, criavam-se outras estratégias para o aluno chegar ao seu "limite" das dores sem ter que diminuir a intensidade dos exercícios físicos. Estas situaçóes eram compreensíveis na medida em que 
o profissional da academia P era reconhecido por levar seus alunos aos "limites" dos esforços físicos:

Juliana: $\mathrm{O}$ abdominal que Lena passou é tão bom que eu tô ferrada desde quarta-feira, hoje é sexta e ainda estou sentindo.

Rayssa: Está demais isso aqui! Tem que doer!

Gabrielle: Muita dor, não tô aguentando mais sustentar o peso!

Andressa: Esses exercícios do professor Cobra são bons! Assim a gente vai parar ali no posto de saúde.

Beatriz: Sinto muita dor a cada série. Eu: É mesmo? Dor? Que tipo de dor?

Beatriz: De malhar, senti muita mudança depois que conheci o professor Cobra. Olha ele vindo aí, vocêe é o nosso salvador da pátria, você mata a gente!

O profissional era "bom porque sacrificava os corpos dos seus alunos". Em contrapartida, aqueles profissionais da academia $\mathrm{P}$ que náo levavam os seus alunos ao "limite" das dores raramente tinham prestígio daqueles que se exercitavam ali. Tendo em vista a ideia de performance de SCHECHNER $^{39}$ e de eficácia nas interaçóes sociais de Goffman ${ }^{38}$, era possível considerar que o profissional para se manter em certo nível de um padrão de "sucesso" e de "excelência" em sua atuação na musculação deveria exigir o máximo dos alunos a ponto de propiciar as dores. Do contrário, na perspectiva de GOFFMAN ${ }^{19}$, se a performance do profissional apresentada ou encenada não se alinhasse aos interesses dos alunos em chegar a certos "limites" corporais, o seu papel social e o seu status perante o público ficava comprometido, isto é, a "malhaçáo" não teria sido tão eficaz.

O corpo do profissional era a prova de que valia a pena se exercitar de forma exaustiva. Ele demonstrava que também conseguia se movimentar no "limite" das dores causadas pelos esforços físicos. Alguns alunos cobravam dos profissionais para se exercitarem com eles durante o expediente de trabalho. Assim, sob os argumentos de que o profissional de Educaçâo Física "deveria dar o exemplo de sujeito 'ativo' e 'forte", os alunos os desafiavam a chegar a determinado "limite" das dores corporais "malhando".

Destarte, o profissional da academia P tinha uma dupla tarefa: a do malhar e a do trabalho. Havia, portanto, a ideia de uma única jornada na medida em que o malhar fazia parte do trabalho. Uma das professoras me dizia que escolhia determinado horário de trabalho para caminhar ou correr na esteira porque, além de se mostrar competente no que fazia, conseguia desfrutar do estabelecimento para si. Um dos professores se exercitava durante o trabalho criando uma espécie de aula coletiva na sala de musculaçáo ao reunir diferentes alunos desafiando quem "sairia vivo" da sequência de abdominais que ficava propondo: ele ou os alunos. Outros profissionais costumavam fazer exercícios físicos alternando com uma orientação pontual; ao mesmo tempo em que instruíam os alunos, mostravam como deveria aguentar as dores.

Dessa forma, durante a atuação profissional, não adiantava somente "falar" como deveria se exercitar quanto aos esforços físicos extenuantes, mas também demonstrá-los na prática da "malhação", servindo como exemplo aos alunos do que era possível aguentar. Isso confirmava a ideia de WACQUANT ${ }^{40}$ que, por vezes, o corpo contém um saber legítimo. Nesse sentido, de maneira semelhante, os profissionais e os alunos compartilhavam a necessidade de alcançar tais "limites" vinculados às dores corporais.

\section{Na academia $G$ do bairro nobre da Barra da Tijuca}

Grande parte do público da academia $G$ possuía uma tendência de amenizar as dores causadas pelos esforços físicos:

\footnotetext{
Monique: Hoje eu trouxe essa série aqui, ó, não vou fazer esse exercício não porque eu já fiz ontem. Caraca, que série é essa? É muito estafante!

Bianca: Dessa série aí, eu vou fazer no máximo duas vezes. Monique: Tá, eu também! Vamos tirar fotos então, quando você fizer, eu bato uma foto sua.

Bianca: Combinado!
}

Eu: Oi, Elaine, que cara é essa?
Elaine: É cara de dor, eu não gosto de sentir muita dor, a
náo ser aquele esforcinho no final quando não está mais
aguentando o peso, aí, tudo bem, mas dores desse tipo não.

$\mathrm{Na}$ academia G, a forma de lidar com as estafas era no sentido de torná-las a menor possível. Os exercícios demasiados em quantidade e intensidade ultrapassando determinados "limites" não eram bem recebidos pelos alunos. Esses alunos respeitavam mais os intervalos entre os exercícios físicos, muitas vezes, ultrapassando o tempo prescrito. Eles descansavam em cima dos aparelhos de musculação e não se demonstravam tão "frenéticos" na realização das práticas corporais. Quando os profissionais realizavam alongamentos nos alunos, esses diziam que não queriam sentir muita dor e, quando começavam a perceber qualquer 
desconforto, pediam para os profissionais pararem de "forçar o movimento" com uma expressão facial de desagrado, sinalizando com a mão para interromper. Muitos alunos ficavam passando a mão na "região acionada” pelo exercício físico como uma espécie de monitorar se "estava tudo bem com o local". Chegavam até simular o movimento sem pesos posteriormente para ver se a articulação estava "normal". Esses alunos abreviavam a duração de tempo de treino recomendado pelo profissional com "cara de dor" alegando que "não precisavam de tanta estafa assim". Antes de executarem os exercícios físicos, os alunos buscavam também formas de fazê-lo reduzindo as estafas. No setor aeróbio, poucos imprimiam um ritmo de esforço longo e intenso e, quando alguém o fazia, pausava do lado do aparelho para descansar ou conversar, beber água ou ainda se sustentar nas barras de segurança no momento de cansaço. Enfim, tantas e inúmeras formas de realizar os exercícios evitando ou minimizando as dores provindas do que denominavam de "treino".

Observava, portanto, que na academia G, em consonância à perspectiva de BoLTANSKI ${ }^{41}$, havia uma tendência mais evidente da valorização da aparência, bem como a desvalorização da força e da energia física nos grupos de camadas sociais mais altas. Ao não optarem por práticas corporais extenuantes, os alunos demonstravam formas de exercitar com menor teor de "brutalidade", como um sinal de distinção. $\mathrm{Na}$ perspectiva de GofFMAN ${ }^{19}$, esses comportamentos e atitudes em interaçóes sociais contêm motivos morais e instrumentais a fim de manter uma "boa impressão" ao outro.

Assim, os alunos faziam questão de deixar evidentes os desconfortos físicos e o temor dos riscos que esses poderiam acarretar. Eles não tinham dificuldade em relatar suas "falhas" em dado desempenho corporal como, por exemplo, que não conseguiram executar um movimento ou que não tiveram força para levantar determinada sobrecarga. Eles não eram mal vistos por isso e nem se consideravam inferiores àqueles que realizavam as práticas corporais com mais quantidade e intensidade. Pelo contrário, ao mencionarem o que estavam sentindo, transparecia que tinham um cuidado minucioso de si face aos riscos que poderiam envolvê-los.

Independentemente se esses alunos despendessem muito dinheiro com as práticas corporais no local, os mesmos não reproduziam esses custos no corpo, como acontecia na academia P. Frequentar e pagar essa academia, considerada cara em relação a outras da cidade, não impedia esses alunos de consumir outros diversos serviços igualmente caros e relacionados aos cuidados com o corpo tais como: salóes de beleza, barbearias, spas, clubes ou até locais considerados de entretenimento como bares, cinemas, viagens, etc. Isso mostrava o poder aquisitivo dos frequentadores e como as academias eram naturalizadas ou faziam parte da rotina diária deles. MALYsse ${ }^{42}$ comenta que "A sala de musculação tornou-se inclusive um lugar tão banal quanto um banheiro, e cada quarteirão da Zona Sul do Rio tem a sua própria academia.” (p. 114).

Nesse contexto da academia G, profissionais de Educação Física e alunos estavam em constante "negociação" em relação aos exercícios físicos. Os professores costumavam acatar o pedido dos "clientes" de se exercitar sem qualquer sensação de dor corporal:

Prof. Régis: Entáo, vamos fazer esse supino aqui.

Eduardo: Pô, tem como eu fazer aquele lá no aparelho, é mais fácil de executar.

Prof. Régis: Mas já trocamos o exercício anterior, quer trocar este também?

Eduardo: Vamos fazer o seguinte, então o anterior a gente não troca, mas este sim, esse exercício me cansa muito.

Newton: Oi, qual é a barra mais leve aqui?

Prof. Roger: É essa aqui! Vai colocar quanto nessa barra?

Newton: Não sei!

Prof. Roger: Vamos pegar cinquenta de cada lado, deixa eu pegar as anilhas aqui.

Newton: Você tá doido? Tá maluco? Quinze ou vinte quilos no máximo!

Prof. Roger: Você quem manda!

O profissional possuía um "menu de estímulos dolorosos" no que diz respeito à quantidade de carga, de repetiçóes de execuçóes e da complexidade dos exercícios físicos. Os alunos, por sua vez, podiam optar pelo nível de dor que gostariam ou não de ter. Rotineiramente, escutava de alguns profissionais que eles eram obrigados a serem "menos agressivos" com os alunos. Diziam que "chegavam devagar" com as dores, pois a "abordagem aos clientes" tinha que ser feita de forma mais "amena" ou de maneira mais "afetiva e paciente” para não espantá-los do estabelecimento. Além disso, a ideia era prescrever um tipo de programa de treinamento que o cliente se identificasse para que se mantivesse na academia.

Assim, havia a lógica de que se o aluno estava "pagando" para realizar as práticas corporais, o professor apenas "vendia" aquilo que era desejado. A viabilidade do ato da prescriçáo era estabelecida e ressignificada no "limite" corporal da percepção de dores de esforços físicos do cliente, mesmo que as orientaçóes dos profissionais 
estivessem encarnadas na racionalidade biomédica quanto à noção de riscos em saúde. Entretanto acatar um pedido do aluno de "não sentir muito esforço físico" náo significava que eles concordavam com essa situação. Pelo contrário, os profissionais irritavam-se com essas atitudes consideradas "inadmissíveis" para quem deveria treinar o corpo no "limite". Essa ideia vai ao encontro da perspectiva de LE BRETON ${ }^{43}$ quando afirma que os profissionais responsáveis por certas modificaçôes corporais se inserem em um comércio de serviços em que, muitas vezes, as suas perspectivas de trabalho ficam submetidas à soberania do cliente com o intuito de manter um lugar no mercado. Desse modo, eventualmente, o elemento "comercial" se sobrepunha ao "técnico-científico".

Enquanto os profissionais viam a musculação como um lugar de "treinar o corpo", um espaço de saúde e de controle de riscos, grande parte dos alunos concebia aquele local como mais um de sua rotina de convívio social. Eles organizavam grandes círculos de conversas entre os aparelhos de musculação demonstrando que o fato de exercitarem ali estaria em segundo plano. A sociabilidade em compartilharem e contarem as suas possibilidades de entretenimento, de investimentos financeiros, de relacionamento no trabalho e na vida pessoal, etc. se sobrepunha às práticas corporais, sobretudo em presença de dor.

Já, para grande parte dos profissionais, como no caso dos professores da academia $\mathrm{P}$, o reconhecimento do trabalho seria contemplado na medida em que o aluno sinalizasse que sentia essa dor de esforço físico. $\mathrm{O}$ fato de sentir esses desconfortos físicos estava relacionado com exercícios físicos eficazes. Isso confirma o relato de Hansen e VAZ10: "[...] praticamente todos os entrevistados, inclusive os professores, consideram normal ou até mesmo prazerosa a sensação de dor durante os exercícios ou mesmo após uma seção de musculaçáo." (p. 143). Igualmente, segundo ToRRI, BASSANi e VAZ $Z^{11}$, "[...] é frequente o uso de diversas estratégias por parte dos professores para incentivar alunos e alunas, especialmente da metade para o final das aulas, a transformarem o desconforto provocado pela dor em um estímulo a mais e na garantia do dever cumprido." (p. 270).

Os profissionais da academia $G$ encerravam a prescrição da rotina de exercícios físicos dos seus alunos somente quando estes mencionavam ou demonstravam de alguma maneira que já tinham chegado ao "limite" dos esforços físicos. Os "limites" das dores prescritos pelos profissionais nunca chegavam ao seu "final" ou raramente eram ultrapassados. Para o profissional da academia G, tornar o aluno em constante busca dos próprios "limites" corporais era também uma forma de manter o cliente engajado nos exercícios físicos no interior do estabelecimento. A prescriçáo de treinamento se mantinha sempre como uma "esperança" de que o corpo chegaria ao "limite".

Assim, por vezes, a atuação do profissional distanciava seus alunos de certas atitudes que poderiam culpabilizálos e estigmatizá-los pelas suas condiçóes ou tipos corporais, isto é, normalizava aqueles que estavam realizando a prática corporal à luz dos seus "limites". No contexto das práticas corporais, pode haver uma valoração distintiva entre vitoriosos - bonitos, fortes $\mathrm{e}$ saudáveis -, e fracassados - fracos, feios e doentes ${ }^{36}$, o que eu observava quando o profissional de Educação Física estimulava ou desafiava os corpos no "limite" com seus alunos. SASSATELLI ${ }^{22}$ comenta que tornar o exercício físico como uma forma de "desafio" atrai consideravelmente os alunos.

\section{Considerações finais}

Conclui-se que os sentidos e os significados atribuídos às dores corporais e aos riscos no que diz respeito aos esforços físicos pelos alunos e pelos profissionais de Educação Física podem ser modulados de formas plurais e dinâmicas em função dos contextos socioeconômicos e culturais das academias e dos grupos que ali frequentam. Destarte, trabalhos etnográficos em academias específicas fornecem uma diversidade de noçóes sobre riscos e processos terapêuticos que ultrapassam o referencial físico-orgânico ${ }^{44}$. Empreendimentos investigativos desse porte tornamse imperiosos na contemporaneidade na medida em que cada vez mais, segundo $\mathrm{BECK}^{45}$, vive-se em uma sociedade de risco caracterizada pela responsabilização do indivíduo, criando, por consequência, uma expansão do perigo social que a todo instante ameaça as suas próprias condutas.

Assim, embora Torri, Bassani e VAZ ${ }^{11}$ tenham afirmado que "O enfrentamento da dor, do sofrimento, do sacrifício e da privação é freqüentemente encarado como algo corriqueiro e 'normal' por parte dos frequentadores de academias." (p. 266), argumento que, a depender das circunstâncias e das interaçóes do face a face do público, tal premissa generalizante deve 
ser revisitada ao visualizar o cotidiano da academia $P$ em comparação à academia G. Em outras palavras, é preciso cada vez mais discutir a pluralidade dos perfis dos públicos frequentadores das diversas academias e as diferentes interações sociais que ali são estabelecidas. Urge a necessidade de não compreender a academia como se fosse um lócus homogêneo de usos do corpo, sobretudo regido apenas pela égide biomédica.

$\mathrm{Na}$ academia P, o exercitar-se se configurava como uma "necessidade" e não um "luxo" para os alunos. Já na academia $G$, ir a tal estabelecimento era um "ato simplesmente corriqueiro" e integrante de um espaço de sociabilidade. Ainda que a estilização da vida fique regrada entre o "luxo" e a "necessidade", caracterizando as preferências distintivas por certos bens culturais que acabam funcionando como marcadores simbólicos de determinadas camadas sociais ${ }^{46}$, vale lembrar que as relaçóes sociais reconstroem-se continuamente no interior dos grupos sociais ${ }^{19}$.

Em suma, comparando as duas academias no que se refere a essas "estafas", era possível compreender que o corpo em determinados segmentos socioeconômicos desfavorecidos, como na academia $\mathrm{P}$, se tornava um "bem" a ser mantido e o "culto" à dor pela "malhação" era uma forma de atingi-lo. Por outro lado, na academia G, preponderava a ideia do corpo "treinado" como um "patrimônio" a ser "protegido" ou um "dote" a ser "preservado" contra qualquer indício de dor ou de risco à saúde.

Nota-se, assim, visóes de mundo peculiares de acordo com os segmentos da sociedade que implicam em múltiplos usos do corpo apresentados cotidianamente para aqueles que atuam nesses espaços de práticas corporais. Ainda que os profissionais de Educação Física estivessem inseridos em diferentes contextos e grupos sociais, havia uma tendência dos mesmos exigirem o máximo de esforços físicos dos seus alunos. Isso vai ao encontro de que analisar padróes de cultura profissional seria um caminho adequado de investigação, pois há um lugar social "comum" em que os profissionais compartilham determinadas concepçóes laborais ${ }^{26}$.

Em síntese, para GoFFMAN"19 "Dentro das paredes do estabelecimento social encontramos uma equipe de atores que cooperam para apresentar à plateia uma dada definição da situação" (p. 218). Desse modo, o período liminar entre "estar" ou "nunca estar" no "limite" para o aluno era infinitamente questionado ou desconstruído pelos profissionais de Educação Física a depender das circunstâncias e interaçóes sociais.

Portanto, esse trabalho apontou como as noçóes "malhar" e "treinar" sugerem que os "limites" desses tipos de dores e as noçóes de risco à saúde em academias indicam os múltiplos lugares sociais cotidianamente exercidos tanto pelos profissionais quanto pelos alunos. Esses aspectos são de suma importância como objeto de investigação e de intervenção no campo da Saúde e na área de Educação Física. Isso se justifica na medida em que lidar com/para/no corpo durante o cotidiano dos serviços exige dos profissionais entender e particularizar a relação com o outro a partir de distintos marcadores sociais de acordo com determinados contextos socioeconômicos e culturais, atuando, assim, com maior efetividade na promoção à saúde. 


\section{Abstract}

No pain, no gain? Pains and risks between work out and train in physical efforts in fitness centers.

The objective of this ethnographic research was to analyze and discuss the meanings attributed to bodily pains and risks regarding to physical efforts by users and Physical Education professionals in two fitness centers in Rio de Janeiro: a small one in a popular neighborhood $(P)$ and a large one in a noble neighborhood $(G)$ of the city. With the theory and methodology of the Symbolic Interactionism, a comparative ethnography occurred in the bodybuilding space of those two fitness centers. The analyses indicated that the edge of pains during exercise and the notions of health risks were represented in plural and dynamic ways according to the contexts and social groups. The professionals at both establishments tended to demand the maximum physical effort from their audiences. In the fitness center $P$, the cult of pain and risk was a way of caring of oneself. Users conceived the body as a "property" to be constantly worked-out. In the fitness center G, sociability was favored as a result of the exhaustion of physical exercises. For the users, feeling pain or being at risk symbolized damage to the body understood as a "patrimony" to be trained. More than a physical-biological data represented by sacrifice and bodily suffering, the manner of feel pain and the comprehension of health risks may reveal the variety of social places of those surveyed. These aspects become important for the production of knowledge and professional intervention in the field of Health and in the Physical Education area, since they help to understand and particularize the actions and academic-professional reflections relating to one another, beyond the technical-scientific referential of biomedical rationality.

KEYwords: Physical Education and Training; Anthropology; Health risk; Physical activity; Bodybuilding; Ethnography.

\section{Referências}

1. Luz MT. Especificidade da contribuição dos saberes e práticas das Ciências Sociais e Humanas para a Saúde. Saúde Soc. 2011;20:22-31.

2. Canesqui AM. Ciências Sociais e saúde no Brasil. São Paulo: Hucitec; 2011.

3. Silva CL, Velozo EL, Rodrigues Júnior JC. Pesquisa qualitativa em Educação Física: possibilidades de construção de conhecimento a partir do referencial cultural. Educ Rev. 2008;48:37-60.

4. Goellner SV, Reppold Filho AR, Fraga AB et al. Pesquisa qualitativa na educação física brasileira: marco teórico e modos de usar. Rev Educ Fís/UEM. 2010;21:381-410.

5. Moura PV, Silva EAPC, Silva PPC et al. O significado da dor física na prática do esporte de rendimento. Rev Bras Ciênc Esporte 2013;35:1005-19.

6. Le Breton D. Condutas de risco: dos jogos de morte ao jogo de viver. Campinas: Autores Associados; 2009.

7. Vaz AF. Educação do corpo, conhecimento, fronteiras. Rev Bras Ciênc Esporte. 2003;24:161-72.

8. Garcia RP. Antropologia do esporte. Rio de Janeiro: Shape; 2007.

9. Cruz RC. El deporte, proyección, espejo y símbolo cultural: reflexión sobre los deportes de sacrificio y su transmisión de valores en el contexto socioeducativo. Movimento. 2013;19:315-36.

10. Hansen R, Vaz AF. Treino, culto e embelezamento do corpo: um estudo em academias de ginástica e musculação. Rev Bras Ciênc Esporte. 2004;26:135-52.

11. Torri G, Bassani JJ, Vaz AF. Dor e tecnificação no contemporâneo culto ao corpo. Pensar Prát. 2007;10:261-73.

12. Silva AC, Ferreira J. Corpos no "limite" e risco à saúde na musculaçáo: etnografia sobre dores agudas e crônicas. Interface (Botucatu). 2017;21:141-51.

13. Helman CG. Cultura, saúde e doença. Porto Alegre: Artes Médicas; 1994.

14. Sarti C. Prefácio. In: Ferreira J, Fleischer S, organizadoras. Etnografias em serviços de saúde. Rio de Janeiro: Garamond; 2014, p. 7-10.

15. Nakamura E. O método etnográfico em pesquisas na área da saúde: uma reflexão antropológica. Saúde Soc. 2011;20:95103. 
16. Le Breton D. Antropología del dolor. Barcelona: Seix Barral; 1999.

17. Silva, AC. "Limites" corporais e risco à saúde na musculação: etnografia comparativa entre duas academias de ginástica cariocas [tese]. Rio de Janeiro (RJ): Universidade Federal do Rio de Janeiro, 2014.

18. Becker H. A escola de Chicago. Mana. 1996; 2:177-88.

19. Goffman E. A representação do eu na vida cotidiana. Petrópolis: Vozes; 2002.

20. Bertevello GJ. Academias de ginástica e condicionamento físico: desenvolvimento. In: DaCosta L, organizador. Atlas do esporte no Brasil. Rio de Janeiro: CONFEF; 2006, p. 63-4.

21. Pasquali D, Niterói R, Mascarenhas F. A indústria do fitness e seu desenvolvimento desigual: um estudo sobre as academias de ginástica na cidade de Goiânia. Pensar Prát. 2011;14:1-15.

22. Sassatelli R. Interaction order and beyond: a field analysis of body culture within fitness gyms. In: Featherstone M, organizador. Body modification. London: Sage; 2000, p. 227-48.

23. Hansen R, Vaz AF. "Sarados" e "gostosas" entre alguns outros: aspectos da educação dos corpos masculinos e femininos em academias de ginástica e musculação. Movimento. 2006;12:133-52.

24. Santos SF, Salles AD. Antropologia de uma academia de musculação: um olhar sobre o corpo e um espaço de representação social. Rev Bras Educ Fís Esporte. 2009;23:87-102.

25. Freitas DC, Silva FAG, Silva AC et al. As práticas corporais nas academias de ginástica: um olhar do professor sobre o corpo fluminense. Rev Bras Ciênc Esporte 2011;33:959-74.

26. Becker HS. Segredos e truques da pesquisa. Rio de Janeiro: Zahar; 2007.

27. Sabo D. Pigskin, patriarchy and pain. In: Kimmel M, Messner M, organizadores. Men's Lives. Nova York: Mcmillan Publishing; 1992, p. 103-8.

28. Sarti CA. A dor, o indivíduo e a cultura. Saúde Soc. 2001;10:3-13

29. Mauss M, Hubert H. Sobre o sacrifício. São Paulo: Cosac Naify; 2005.

30. Turner VW. O processo ritual: estrutura e antiestrutura. Petrópolis: Vozes; 1974.

31. Gennep AV. Os ritos de passagem. Petrópolis, RJ: Vozes; 2011.

32. Schechner R. Performers e espectadores: transportados e transformados. Moringa 2011;2:155-85.

33. Coelho Filho CAA. O corpo em questáo: metamorfose psíquica a partir das atividades físicas. $25^{\circ}$ Congresso Brasileiro de Ciências da Comunicação; 2002; Salvador, BR. Salvador: UERJ; 2002. p. 1-11

34. Rodriguez AD. Si te duele es porque estás entrenando bien. La sensación paradójica de dolor corporal en los gimnasios de fitness de la Ciudad Autónoma de Buenos Aires. Movimento. 2017;23:743-54.

35. Palma A, Ferreira DC, Bagrichevsky M et al. Dimensóes epidemiológicas associativas entre indicadores socioeconômicos de vida e prática de exercícios físicos. Rev Bras Cienc Esporte. 2006;27:119-36.

36. Sabino C. O peso da forma: cotidiano e uso de drogas entre fisiculturistas [tese]. Rio de Janeiro (RJ): Universidade Federal do Rio de Janeiro, Instituto de Filosofia e Ciências Sociais; 2004.

37. Shilling C. The body and social theory. London: Sage; 2005.

38. Goffman E. Ritual de interação: ensaios sobre o comportamento face a face. Petrópolis: Vozes; 2011.

39. Schechner R. Performance studies: an introduccion. New York \& London: Routledge; 2006.

40. Wacquant L. Corpo e alma: notas etnográficas de um aprendiz de boxe. Rio de Janeiro: Relume Dumará; 2002.

41. Boltanski L. As classes sociais e o corpo. Rio de Janeiro: Graal; 1984.

42. Malysse S. Em busca dos (h)alteres-ego. In: Goldenberg M, organizadora. Nu \& Vestido: dez antropólogos revelam a cultura do corpo carioca. Rio de Janeiro: Record; 2007, p. 79-137.

43. Le Breton D. Sinais de identidade: tatuagens, piercings e outras marcas corporais. Lisboa: Miosótis; 2004.

44. Andrews GJ, Sudwell MI, Sparkes AC. Towards a geography of fitness: an ethnographic case study of the gym in British bodybuilding culture. Soc Sci Med. 2005;60:877-891.

45. Beck U. Sociedade de risco: rumo a uma outra modernidade. São Paulo: Editora 34; 2011.

46. Bourdieu P. Sociologia. São Paulo: Ática; 1983. 
ENDEREÇO

Alan Camargo Silva

Avenida Carlos Chagas Filho, 540

Ilha do Fundão - Cidade Universitária

21941-598 - Rio de J aneiro - RJ - Brasil

E-mail: alan10@zipmail.com.br
Submetido: 01/ 08/2017

Revisado: 07/04/2018

Aceito: 08/08/2018 